\title{
Prevalence and validity of self-reported smoking in Indigenous and non-Indigenous young adults in the Australian Northern Territory
}

\author{
Mark S Pearce ${ }^{1 *}$, Kay D Mann ${ }^{1}$, Gurmeet Singh², Belinda Davison² and Susan M Sayers ${ }^{2}$
}

\begin{abstract}
Background: In this study, we used data from Australia's Northern Territory to assess differences in self-reported smoking prevalence between the Indigenous and non-Indigenous populations. We also used urinary cotinine data to assess the validity of using self-reported smoking data in these populations.

Methods: The Aboriginal Birth Cohort (ABC) is a prospective study of 686 Aboriginal babies born in Darwin 1987-90. The Top End Cohort (TEC) is a study of non-Indigenous adolescents, all born in Darwin 1987-91. In both studies, participants aged between 16 and 21 years, were asked whether they smoked. Urinary cotinine measurements were made from samples taken at the same visits.

Results: Self-reported smoking prevalence was $68 \%$ in the ABC and $14 \%$ in the TEC. Among the self-reported non-smokers, the median cotinine levels were higher in the $A B C(33 \mathrm{ng} / \mathrm{ml})$ than in the TEC $(5 \mathrm{ng} / \mathrm{ml})$, with greater percentages of reported non-smokers in the under $50 \mathrm{ng} / \mathrm{ml}$ group in the TEC than in the ABC

Conclusions: Prevalence of smoking was much higher in the ABC than in the TEC. The higher cotinine levels in $A B C$ non-smokers may reflect an underestimated prevalence, but is also likely to reflect higher levels of passive smoking. A broader approach encompassing social, cultural and language factors with increased attention to smoking socialisation factors is required.
\end{abstract}

Keywords: Cigarette smoking, Validation, Cotinine, Aboriginal Australians, Passive smoking

\section{Background}

Tobacco smoking is the single most preventable cause of ill health and death in Australia and is estimated to be the cause of 15,000 deaths in the country per year [1]. Although smoking rates are declining currently in both Indigenous and non-Indigenous people in Australia, marked discrepancies remain between Indigenous and non-Indigenous rates and their rates of decline [2]. After adjusting for differences in the age structures of the two populations, daily smoking was 2.2 times more common among Indigenous people aged 15 years or older in 2010 than among their non-Indigenous counterparts (38\% and $18 \%$, respectively [3]). Furthermore, a comparison of trends of smoking prevalence among Indigenous and non-

\footnotetext{
* Correspondence: mark.pearce@ncl.ac.uk

'Institute of Health \& Society, Newcastle University, Sir James Spence

Institute, Royal Victoria Infirmary, Newcastle upon Tyne, UK

Full list of author information is available at the end of the article
}

Indigenous Australian secondary school students showed that rates declined between 1996 and 2005 for both groups [4]. However, the rate of decline differed, with a steady decline across the entire study period for the nonIndigenous students compared to a decline only between 1999 and 2002 for Indigenous students [4]. The majority of cigarette smokers begin smoking in childhood or adolescence [5], with smoking initiation usually completed by 25 years of age [6,7]. In order to inform different intervention strategies to further reduce initiation and prevalence of smoking in young Australians, it is important to explore the differences in smoking prevalence between adolescent non-Indigenous and Indigenous Australians.

Smoking behaviours are most often assessed by questionnaire, which is prone to inaccurate responses and underestimation of the true prevalence of cigarette smoking [8-10]. This has prompted a number of studies to attempt to validate smoking questionnaire responses, 
for example by using exhaled carbon monoxide [10-12], serum, plasma or urine levels of nicotine [13], cotinine [13-19] or thiocyanate [11], the bogus pipeline approach [20], or store turnover of cigarettes, as was done previously in the context of remote Indigenous Australians [21]. Among the findings from such studies have been differences in the validity of self-reported smoking by sex [10,19] and ethnicity [19]. Therefore, in addition to assessing whether smoking prevalence differs between different population groups, it is also crucial to assess whether differences in reliability also exist in order to assess the validity of the prevalence estimates.

In this study we used data and samples from two cohorts, the Indigenous Aboriginal Birth Cohort (ABC) $[22,23]$ and the non-Indigenous Top End Cohort (TEC) [24] with two aims; i) to assess smoking prevalence from self-report questionnaire data and, ii) to assess validity of self-reported smoking, using urinary measures of cotinine. Both cohorts are based in the Australian Northern Territory (NT).

\section{Methods}

The Life Course Program based at the Menzies School of Health Research is composed of two distinct, but complementary, cohorts. The $\mathrm{ABC}$ is a prospective study of 686 Aboriginal babies (a representative samples of the 1238 eligible babies) recruited at Royal Darwin Hospital between January 1987 and March 1990 to a mother recorded as Aboriginal in the Delivery Suite Register [22]. Data used in this analysis were obtained during followup between December 2005 and January 2008, in over 40 different locations in the 'Top End' of the NT [23].

The TEC is a study of 195 non-Indigenous adolescents, age- and sex-matched to the ABC study participants, born in Darwin between 1987 and 1991 (contemporaneous interval with the $\mathrm{ABC}$ ) and still residing in non-remote locations within the Top End at the time of recruitment [24]. The numbers of non-Indigenous people in remote areas of the NT are very few and this is largely a transient population. Recruitment occurred between November 2007 and September 2009 and involved young people from secondary and tertiary schools, as well as those in employment and unemployed. Inclusion was limited to people born to non-Indigenous mothers as the $\mathrm{ABC}$ study encompassed those people. Both studies were approved by the Human Research Ethics Committee (HREC) of the Northern Territory Department of Health and the Menzies School of Health Research $(A B C$ reference number 05/26, TEC reference number $07 / 20$ ). The ABC study also obtained approval from the Aboriginal Ethical Sub-committee which has the power of veto.

The residence of $\mathrm{ABC}$ participants was classified as 'non-remote' (living within the urban areas of Darwin and its satellite city Palmerston) and 'remote' (living in a rural community with an Aboriginal council, a rural town, or a town camp). All TEC participants resided in urban areas of Darwin and its satellite city Palmerston, hence were all 'non-remote'.

Both the $\mathrm{ABC}$ and TEC underwent a comprehensive health check with cohort members aged between 16 and 21 years.

\section{Self-reported smoking}

For both the ABC and TEC, details on smoking status (current smoker or non-smoker) were self-reported as part of a lifestyle questionnaire (Appendix) including smoking of tobacco and marijuana and consumption of alcohol. The questions used were chosen as they had been developed and used previously in a remote Aboriginal setting [25]. The participants had the choice of answering the questionnaires on a laptop or a paper version. Participants, particularly those in remote areas, answered these questions as they were read out to them by the study team.

\section{Measurement of cotinine}

During the medical examinations, questionnaires were completed, urine samples were collected and cotinine levels were measured. A cut-off of $50 \mathrm{ng} / \mathrm{ml}$ was used to verify non-smokers in accordance with previously published papers $[14,17,19]$. Further cut-off points of 170 , 550 and $2100 \mathrm{ng} / \mathrm{ml}$, as used by Zielińska-Danch et al. [17], have been used for descriptive purposes.

\section{Statistical analysis}

Prevalence/percentage figures with 95\% confidence intervals $(95 \% \mathrm{CI})$ were calculated and chi-squared tests for associations between smoking and cohort, sex and residential region ( $\mathrm{ABC}$ only) were done using a $\mathrm{p}$-value less than 0.05 for statistical significance. Urinary cotinine was treated as a continuous measurement and all other variables were treated as categorical. Comparisons of cotinine levels between groups were done using the Wilcoxon rank-sum test. All statistical analyses were done using the Stata statistical software package, version 12.0 (StataCorp, College Station, TX).

\section{Results}

Self-reported smoking data were available for 407 (197 male) participants of the $\mathrm{ABC}$ and for 182 (78 male) of the TEC. Average age at assessment for those with smoking data was similar between the cohorts (mean (sd) was 17.9 (1.13) for the ABC and 18.1 (1.38) for the TEC). Self-reported smoking prevalence was significantly different between the cohorts $(\mathrm{p}<0.0001)$, with $68 \%$ prevalence in the $\mathrm{ABC}$ and $14 \%$ prevalence in the TEC (Table 1). Prevalence rates were similar for males and 
Table 1 Self-reported smoking prevalence by cohort, sex and, for the $A B C$ only, residential area

\begin{tabular}{llll}
\hline & \multicolumn{3}{l}{ Self-reported smoking } \\
\cline { 2 - 4 } & $\mathbf{n}$ & Prevalence & $\mathbf{9 5 \% ~ C I}$ \\
\hline ABC & 407 & 0.68 & $0.63,0.72$ \\
Overall & 197 & 0.69 & $0.63,0.76$ \\
Men & 210 & 0.67 & $0.60,0.73$ \\
Women & 320 & 0.69 & $0.64,0.75$ \\
Remote residence & 85 & 0.64 & $0.54,0.74$ \\
Non-remote residence & & & \\
TEC & 182 & 0.14 & $0.08,0.19$ \\
Overall & 78 & 0.13 & $0.03,0.21$ \\
Men & 104 & 0.14 & $0.06,0.22$ \\
Women & &
\end{tabular}

95\% Cl: 95\% Confidence Interval.

females $\left(\chi^{2}=0.26, \mathrm{df}=1, \mathrm{p}=0.61\right.$ for the $\mathrm{ABC}$ and $\chi^{2}=$ $0.10, \mathrm{df}=1, \mathrm{p}=0.76$ for the TEC) and also for remote and non-remote residential areas in the $\mathrm{ABC}\left(\chi^{2}=1.06\right.$, $\mathrm{df}=1, \mathrm{p}=0.30)$. Six participants in the $\mathrm{ABC}(1.5 \%)$ and 12 in the TEC used to smoke, but were current nonsmokers. No-one in either cohort reported using nicotine replacement therapy at the time of the study.

Valid urinary cotinine measurements were available for 391 of the $\mathrm{ABC}$ and 156 of the TEC. Descriptive summaries of the median cotinine levels by selfreported smoking status are given in Table 2, by cohort, sex and, for the $\mathrm{ABC}$ only, residential area. Among the self-reported smokers, the median cotinine levels were higher in the $\mathrm{ABC}(1300 \mathrm{ng} / \mathrm{ml})$ than in the TEC (480 ng/ml), Wilcoxon $\mathrm{p}<0.0001$. Similarly, median cotinine levels among self-reported non-smokers were higher in the ABC $(33 \mathrm{ng} / \mathrm{ml})$ than in the TEC (5 ng/ $\mathrm{ml}$ ), Wilcoxon $\mathrm{z}=15.63, \mathrm{p}<0.0001$.
Of the 124 participants in the $\mathrm{ABC}$ that self-reported non-smoking, 58 (47\%) recorded cotinine levels higher than $50 \mathrm{ng} / \mathrm{ml}$ (the cut-off usually used for nonsmokers), while of the 267 self-reported smokers, 17 (6\%) had cotinine levels less than $50 \mathrm{ng} / \mathrm{ml}$ (Table 3). In contrast, 129 (98\%) of the TEC self-reported nonsmokers had cotinine levels of less than $50 \mathrm{ng} / \mathrm{ml}$, with the remaining three all under $170 \mathrm{ng} / \mathrm{ml}$. However, in self-reported smokers $(\mathrm{n}=24), 14$ had cotinine levels less than $50 \mathrm{ng} / \mathrm{ml}$, with three of those having the minimum level $(5 \mathrm{ng} / \mathrm{ml})$ recorded. The percentage of self-reported non-smokers above the $50 \mathrm{ng} / \mathrm{ml}$ cut-off was higher in women than men in the $\mathrm{ABC}$, but very similar in the TEC. The proportion of self-reported non-smokers in the $\mathrm{ABC}$ remote group with cotinine levels above the $50 \mathrm{ng} / \mathrm{ml}$ cut-off was over three times that seen in the $\mathrm{ABC}$ non-remote group.

\section{Discussion}

In this study of adolescents from Australia's Northern Territory, we have shown striking differences in prevalence of self-reported smoking between the Indigenous and non- Indigenous cohorts. Among self-reported smokers, the median urinary cotinine measures were far greater in the $\mathrm{ABC}$ participants than their smoking counterparts in the TEC. Of those self-reporting that they did not smoke, nearly half of the $\mathrm{ABC}$ cohort had cotinine levels that suggest considerable exposure to cigarette smoke, while the percentage in the TEC with this was negligible.

Self-reported smoking prevalence was $68 \%$ in the $A B C$ and only $14 \%$ in the TEC. The difference in prevalence rates does not appear to be due to residential location, with similar rates seen in the $\mathrm{ABC}$ for both the remote and non-remote populations. Further, there was little difference in mean age between the cohorts, ruling age

Table 2 Summaries of urinary cotinine levels $(\mathrm{ng} / \mathrm{ml})$ by self-reported smoking status, sex, cohort and, for the ABC only, residential area

\begin{tabular}{|c|c|c|c|c|c|c|}
\hline & \multicolumn{3}{|c|}{ Self-reported non-smokers } & \multicolumn{3}{|c|}{ Self-reported smokers } \\
\hline & $\mathbf{N}$ & Median (IQR) & Range & $\mathrm{N}$ & Median (IQR) & Range \\
\hline \multicolumn{7}{|l|}{$A B C$} \\
\hline All & 124 & $33(5,975)$ & 5,3780 & 267 & $1300(825,1810)$ & 5,4990 \\
\hline Men & 56 & $19(9,1120)$ & 5,2620 & 130 & $1375(870,1910)$ & 5,4990 \\
\hline Women & 68 & $54(10,920)$ & 5,3780 & 137 & $1260(725,1740)$ & 5,4920 \\
\hline Remote & 95 & $150(12,1250)$ & 5,3780 & 216 & $1330(868,1785)$ & 5,4990 \\
\hline Non-remote & 29 & $7(5,27)$ & 5,1760 & 51 & $1200(650,1920)$ & 5,3180 \\
\hline \multicolumn{7}{|l|}{ TEC } \\
\hline All & 132 & $5(5,5)$ & 5,530 & 24 & $480(17,928)$ & 5,1850 \\
\hline Men & 60 & $5(5,5)$ & 5,82 & 9 & $950(760,1350)$ & 14,1560 \\
\hline Women & 72 & $5(5,5)$ & 5,530 & 15 & $72(10,545)$ & 5,1850 \\
\hline
\end{tabular}

IQR: Inter-quartile Range. 
Table 3 Numbers (\%) in each urinary cotinine group by self-reported smoking status and cohort, sex and, for the ABC only, residential area

\begin{tabular}{|c|c|c|c|c|c|c|}
\hline & & \multicolumn{5}{|c|}{ Urinary cotinine level $(\mathrm{ng} / \mathrm{ml})$} \\
\hline & & $0-50$ & $51-170$ & $171-550$ & $551-2100$ & $2101+$ \\
\hline \multicolumn{7}{|l|}{$A B C$} \\
\hline All & Smokers & $17(6)$ & $8(3)$ & $22(8)$ & $174(65)$ & $46(17)$ \\
\hline All & Non-Smokers & $66(53)$ & $9(7)$ & $6(5)$ & $36(29)$ & $7(6)$ \\
\hline Men & Smokers & $6(5)$ & $3(2)$ & $10(8)$ & $84(64)$ & $27(21)$ \\
\hline Men & Non-Smokers & $34(61)$ & $2(4)$ & $2(4)$ & $16(29)$ & $2(4)$ \\
\hline Women & Smokers & $11(8)$ & $5(4)$ & $12(9)$ & $90(66)$ & $19(14)$ \\
\hline Women & Non-Smokers & $32(47)$ & $7(10)$ & $4(6)$ & $20(29)$ & $5(7)$ \\
\hline Remote & Smokers & $11(5)$ & $8(4)$ & $17(8)$ & $145(67)$ & $35(16)$ \\
\hline Remote & Non-Smokers & $42(44)$ & $6(6)$ & $6(6)$ & $34(36)$ & $7(7)$ \\
\hline Non-remote & Smokers & $6(12)$ & $0(0)$ & $5(10)$ & $29(57)$ & $11(22)$ \\
\hline Non-remote & Non-Smokers & $24(83)$ & $3(10)$ & $0(0)$ & $2(7)$ & $0(0)$ \\
\hline \multicolumn{7}{|l|}{ TEC } \\
\hline All & Smokers & $8(33)$ & $2(8)$ & $4(17)$ & $10(42)$ & $0(0)$ \\
\hline All & Non-Smokers & $129(98)$ & $2(2)$ & $1(1)$ & $0(0)$ & $0(0)$ \\
\hline Men & Smokers & $2(22)$ & $0(0)$ & $(0)$ & $7(78)$ & $0(0)$ \\
\hline Men & Non-Smokers & $58(97)$ & $2(3)$ & $0(0)$ & $0(0)$ & $0(0)$ \\
\hline Women & Smokers & $6(40)$ & $2(13)$ & $4(27)$ & $3(20)$ & $0(0)$ \\
\hline Women & Non-Smokers & 71 (99) & $0(0)$ & $1(1)$ & $0(0)$ & $0(0)$ \\
\hline
\end{tabular}

Percentages do not add up to 100 in all cases due to rounding.

at assessment out as a confounder. Our results are consistent with a previous study of a sample of Indigenous Australians in Arnhem Land, NT, which reported that $75 \%$ of a sample of 400 individuals aged over 16 years self-reported smoking [12]. These exceptional smoking rates in the Indigenous population of the 'Top End' of the NT appear to have changed little over the past twenty years, with rates consistently over 60\% [26].

The use of self-reported smoking surveys in epidemiological studies is a crucial and common method used to obtain information on a major risk factor for many diseases, in addition to assessing smoking prevalence. However, it is useful to corroborate self-reported smoking data using one of a number of biochemical markers [10]. The actual choice of biochemical marker to be used will often depend on factors other than the scientific validity of the marker, but more on the feasibility of obtaining the biological material and how crucial the accurate determination of smoking status is. Measures based on tests of blood are invasive and are unable to provide an immediate assessment. Less invasive are urine tests, which for urinary cotinine can provide an almost immediate measure of smoking status. As a result, urinary cotinine is a widely used proxy metabolite for nicotine, used to distinguish between active and passive or nonsmokers [27].
We used a discriminative cut-off of $50 \mathrm{ng} / \mathrm{ml}$, in line with previous studies $[14,17,19]$. Among self-reported smokers, the average urinary cotinine measures were far greater in the ABC participants than in the TEC. Not only was there a greater prevalence of smoking in the $\mathrm{ABC}$, but these results suggest heavier smoking, as well as a greater exposure to passive smoking. A previous study of the Aboriginal and Torres Strait Islander people showed that while rates of heavy smoking had decreased between 1994 and 2008 in that population, the rates of light smoking had increased [7]. Regardless, for the ABC population, the levels of smoking remain relatively high.

Of those self-reporting that they did not smoke, nearly half of the $\mathrm{ABC}$ cohort had cotinine levels that suggest considerable exposure to cigarette smoke, perhaps through inaccurate responses to the questionnaire, or due to high levels of passive smoking from the cigarette smoking of family and others, consistent with the overall high prevalence of smoking in this population and setting. This was in contrast to the TEC where only two percent of 'non-smokers' fell into this category. Gilligan et al. [18] used a cut-point of $250 \mathrm{ng} / \mathrm{ml}$ to allow for the high levels of passive smoking in Indigenous households. Even using this much higher cut-point would still have resulted in 47 (36\% of the $\mathrm{ABC}$ self-reported non-smokers) being above the 
cut-point, with just one self-reported non-smoking TEC member above $250 \mathrm{ng} / \mathrm{ml}$. A previous study of the validity of self-reported smoking in a remote Aboriginal community also used cotinine, but found good agreement between the self-report and cotinine measures [16]. n contrast to that study, the study members included in the investigation of validity in the $A B C$ were all young adults, and it is possible that accuracy of responses to questionnaires may vary with age group. There does not appear to be a validity issue with the TEC participants. This is consistent with previous findings of different levels of validity of self-report smoking responses between ethnic groups [10]. Differences in cotinine levels between males and females may reflect different levels of smoking and passive smoking, but also including pre-menopausal groups of women with likely differential cotinine metabolism [28]. It is also possible that high levels of cotinine in light smokers may reflect compensatory smoking where individuals smoke fewer cigarettes per day, but draw back harder and absorb more nicotine per cigarette than a heavier smoker may [29].

While the differences in smoking rates between the cohorts may represent socio-economic disadvantage to some extent, it is also likely that other factors such as cultural differences in views regarding smoking initiation play an important role. This includes a long-standing historical antecedent in the way in which tobacco is currently viewed by Indigenous communities [30]. For example, it became a form of currency when obtaining payment for labour and for settling disputes [30]. In a qualitative study of Australian Aboriginal women, young girls were found to start and continue smoking as a way of attaining status and asserting their Aboriginal identity such that it is seen as belonging to the group, rather than rebelling against it [31]. A more recent study has also shown family and peer influences play a central role in smoking uptake with Indigenous youth [32], reporting high levels of smoking role models and smoking socialisation practices, consistent with the high nicotine levels in the non-smokers in our study.

Limitations of this study relate to the recruitment of the study subjects. The ABC participants were nested within a birth cohort study and are representative of the Indigenous population across the Top End of Australia in that age group. The TEC participants of a similar age were not recruited at birth and may be seen as a select group interested in their health and, perhaps, less likely to be smokers. This could introduce some selection bias, although it is unlikely to account for the large differences seen in this study. Further, while the same questionnaires were used for both populations, the $\mathrm{ABC}$ participants mostly needed these to be read out to them while the TEC were able to answer the questions without assistance. The greater degree of anonymity provided by self-administration of the questionnaires may have had a bearing on the truthfulness of the responses received. This could explain some of the differences in the two cohorts, but is also unlikely to completely explain the differences between the populations.

The questionnaire was limited to smoking status of participants of the ABC and TEC and did not include any information on family smoking status or environmental exposures. However, a previous study in 2008 has shown that $63 \%$ of Aboriginal and Torres Strait Islander children aged 0-14 years lived in a household with members who were daily smokers $(72 \%$ in remote and $61 \%$ in non-remote areas) [33]. The NT has the worst record in overall tobacco control in Australia and was awarded the Dirty Ashtray Award for the worst performing jurisdiction in nine of the seventeen years it has been awarded since 1994 [34]. It was omitted from the national competition after it ranked last for the fourth consecutive year in 2009 [34].

\section{Conclusion}

While tobacco control in NT has improved since 2009 [34], extra resources are needed in the NT, particularly to aid reductions in smoking prevalence in the Aboriginal population. Given the large discrepancies in smoking prevalence between the populations and persistent high levels of smoking among Indigenous young adults, this suggests that current tobacco control approaches and are in need of revision and expansion to tailor to the needs of the Indigenous population. It is likely that a broader approach encompassing social, cultural and language factors with increased attention to smoking socialisation factors is required. The cultural and language knowledge of Indigenous health workers may well be the key to these interventions [26,35], although improvements in the reach of and access to services, and in the services themselves is also required.

\section{Appendix}

The questions on smoking used in the study.

Do you smoke tobacco?

$\square$ no $\square$ used to $\square$ yes

If yes

How often do you smoke?

$\square$ rarely $\square$ weekly $\square$ daily

How many smokes would you have?

How old were you when you started smoking?

If used to

How old were you when you started smoking?

How old were you when you stopped smoking?

Do you smoke marijuana (dope)?

$\square$ no $\square$ used to $\square$ yes

If yes 
How often do you smoke?

$\square$ rarely $\square$ weekly $\square$ daily

How many smokes would you have?

How old were you when you started smoking?

If used to

How old were you when you started smoking?

How old were you when you stopped smoking?

\section{Competing interests}

The authors declare that they have no competing interests.

\section{Authors' contributions}

All authors discussed the original idea for this manuscript. GS and BD were responsible for data collection. KDM and MSP analysed the data and drafted the paper, with critical comments from all other authors. All authors read and approved the final manuscript.

\section{Acknowledgments}

We thank the dedicated $A B C$ research team who traced participants and collected the data and who recruited and collected data from the TEC. We thank the young adults belonging to the ABC and TEC cohorts for their co-operation and all the individuals who helped in the urban and rural locations. This work was supported by the National Health and Medical Research Council of Australia. MSP and KDM's collaboration with this study was funded by a Royal Society Travel Exchange Award.

\section{Author details}

'Institute of Health \& Society, Newcastle University, Sir James Spence Institute, Royal Victoria Infirmary, Newcastle upon Tyne, UK. ${ }^{2}$ Menzies School of Health Research, Charles Darwin University, Darwin, Australia.

Received: 9 January 2014 Accepted: 5 August 2014

Published: 21 August 2014

\section{References}

1. Begg S, Vos T, Barker B, Stevenson C, Stanley L, Lopez A: The Burden of Disease and Injury in Australia 2003. Canberra: Australian Institute of Health and Welfare; 2007.

2. Gartner CE, Barendregt JJ, Hall WD: Predicting the future prevalence of cigarette smoking in Australia: how low can we go and by when? Tob Control 2009, 18:183-189.

3. Australian Institute of Health and Welfare: 2010 National Drug Strategy Household Survey Report. Canberra: Australian Institute of Health and Welfare; 2011.

4. White $\mathrm{V}$, Mason T, Briggs $\mathrm{V}$ : How do trends in smoking prevalence among indigenous and non-indigenous Australian secondary students between 1996 and 2005 compare? Aust N Z J Public Health 2009, 33:147-153.

5. Carson KV, Brinn MP, Labiszewski NA, Peters M, Chang AB, Veale A, Esterman AJ, Smith BJ: Interventions for tobacco use prevention in Indigenous youth. Cochrane Database Syst Rev 2012, 8:CD009325.

6. Messer K, Pierce JP: Changes in age trajectories of smoking experimentation during the California Tobacco Control Program. Am J Public Health 2010, 100:1298-1306.

7. Thomas DP: Changes in smoking intensity among Aboriginal and Torres Straits Islander people, 1994-2008. Med J Aust 2012, 197:503-506.

8. Colletti G, Supnick JA, Abueg FR: Assessment of the relationship between self-reported smoking rate and Ecolyzer measurement. Addict Behav 1982, 7:183-188.

9. Coultas DB, Howard CA, Peake GT, Skipper BJ, Samet JM: Discrepancies between self-reported and validated cigarette smoking in a community survey of New Mexico Hispanics. Am Rev Respir Dis 1988, 137:810-814.

10. Pearce MS, Hayes L: Self-reported status and exhaled carbon monoxide: results from two population-based epidemiologic studies in the North of England. Chest 2005, 128:1233-1238.

11. Morabia A, Bernstein MS, Curtin F, Berode M: Validation of self-reported smoking status by simultaneous measurement of carbon monoxide and salivary thiocyanate. Prev Med 2001, 2:82-88.

12. MacLaren DJ, Conigrave KM, Robertson JA, Ivers RG, Eades S, Clough AR: Using breath carbon monoxide to validate self-reported tobacco smoking in remote Australian Indigenous communities. Popul Health Metrics 2010, 8:2

13. Man CN, Fathelrahman Al, Harn GL, Lajis R, Samin AS, Omar M, Awang R, Bayanuddin NA: Correlation between urinary nicotine, cotinine and self-reported smoking status among educated young adults. Environ Toxicol Pharmacol 2009, 28:92-96.

14. Jarvis MJ, Tunstall-Pedoe H, Feyerabend C, Vesey C, Saloojee Y: Comparison of tests used to distinguish smokers from nonsmokers. Am J Public Health 1987, 77:1435-1438.

15. Vartiainen E, Seppälä T, Lillsunde P, Puska P: Validation of self reported smoking by serum cotinine measurement in a community-based study. J Epidemiol Community Health 2002, 56:167-170.

16. McDonald SP, Maguire GP, Hoy WE: Validation of self reported cigarette smoking in a remote Australian Aboriginal community. Aust N Z J Public Health 2003, 27:57-60

17. Zielińska-Danch W, Wardas W, Sobczak A, Szoltysek-Boldys I: Estimation of urinary cotinine cut-off points distinguishing non-smokers, passive and active smokers. Biomarkers 2007, 12:484-496.

18. Gilligan C, Sanson-Fisher R, Eased S, Wenitong M, Panaretto K, D'Este C: Assessing the accuracy of self-reported smoking status and impact of passive smoke exposure among pregnant Aboriginal and Torres Strait Islander women using cotinine biochemical validation. Drug Alcohol Rev 2010, 29:35-40.

19. Park SW, Kim JY: Validity of self-reported smoking using urinary cotinine among vocational high school students. J Prev Med Health 2009, 42:223-230.

20. Adams J, Parkinson L, Sanson-Fisher RW, Walsh RA: Enhancing self-report of adolescent smoking: the effects of bogus pipeline and anonymity. Addict Behav 2008, 33:1291-1296.

21. Thomas DP, Fitz JW, Johnston V, Townsend J, Kneebone W: Wholesale data for surveillance of Australian Aboriginal tobacco consumption in the Northern Territory. Tob Control 2011, 20:291-295.

22. Sayers SM, Mackerras D, Singh G, Bucens I, Flynn K, Reid A: An Australian birth cohort: a unique resource for a life course study of an indigenous population. A study protocol. BMC Int Health Hum Rights 2003, 3:1

23. Sayers SM, Singh G, Mackerras D, Lawrance M, Gunthorpe W, Jamieson L, Davison B, Schultz K, Fitz J: Australian Aboriginal Birth Cohort Study: follow-up processes at 20 years. BMC Int Health Hum Rights 2009, 9:23.

24. Davison B, Cunningham T, Singh G: Engaging adolescents and young adults in a longitudinal health study: experience from the Top End cohort. Aust N Z J Public Health 2011, 35:86-87.

25. Clough AR, Lee KSK, Cairney S, Maruff P, O'Reilly B, D'Abbs P, Conigrave KM: Changes in cannabis use and its consequences over 3 years in a remote indigenous population in northern Australia. Addiction 2006, 101:696-705.

26. Robertson JA, Conigrave KM, Ivers R, Usher K, Clough AR: Translation of tobacco policy into practice in disadvantaged and marginalized subpopulations: a study of challenges and opportunities in remote Australian Indigenous communities. Health Res Policy Syst 2012, 10:23.

27. Goniewicz ML, Eisner MD, Lazcano-Ponce E, Zielinska-Danch W, Koszowski B, Sobczak A, Havel C, Jacob P, Benowitz NL: Comparison of urine cotinine and the tobacco-specific nitrosamine metabolite 4-(methylnitrosamino)1-(3-pyridyl)-1-butanol (NNAL) and their ratio to discriminate active from passive smoking. Nicotine Tob Res 2011, 13:202-208.

28. Benowitz NL, Lessov-Schlaggar CN, Swan GE, Jacob P: Female sex and oral contraceptive use accelerate nicotine metabolism. Clin Pharmacol Ther 2006, 79:480-488.

29. Benowitz NL, Jacob P, Bernert JT, Wilson M, Wang L, Allen F, Dempsey D: Carcinogen exposure during short-term switching from regular to "light" cigarettes. Cancer Epidemiol Biomarkers Prev 2005, 14:1376-1383.

30. Brady M: Historical and cultural roots of tobacco use among Aboriginal and Torres Strait Islander people. Aust N Z J Public Health 2002, 26:120-124.

31. Passey ME, Gale JT, Sanson-Fisher RW: "It's almost expected": rural Australian Aboriginal women's reflections on smoking initiation and maintenance: a qualitative study. BMC Womens Health 2011, 11:55.

32. Johnston $V$, Thomas DP: Smoking behaviours in a remote Australian Indigenous community: the influence of family and other factors. Soc Sci Med 2008, 67:1708-1716.

33. Australian Bureau of Statistics: The Health and Welfare of Australia's Aboriginal and Torres Strait Islander Peoples. Canberra, Australia: Australian Bureau of Statistics; 2010 
34. Northern Territory Tobacco Control Advisory Committee: Annual Report 2012. Darwin: Northern Territory Government Department of Health; 2012.

35. Thompson M: The best bang for our buck: recommendations for the provision of training for tobacco action workers and Indigenous health workers. Contemp Nurse 2010, 37:90-91.

doi:10.1186/1471-2458-14-861

Cite this article as: Pearce et al:: Prevalence and validity of self-reported smoking in Indigenous and non-Indigenous young adults in the Australian Northern Territory. BMC Public Health 2014 14:861.

\section{Submit your next manuscript to BioMed Central and take full advantage of:}

- Convenient online submission

- Thorough peer review

- No space constraints or color figure charges

- Immediate publication on acceptance

- Inclusion in PubMed, CAS, Scopus and Google Scholar

- Research which is freely available for redistribution 